\title{
A MODIS-based modeling scheme for the estimation of downward surface shortwave radiation under cloud-free conditions
}

\author{
Eslam Javadnia $^{1}$ • Ali Akbar Abkar ${ }^{1} \cdot$ Per Schubert $^{2}$
}

Received: 28 November 2016 / Accepted: 1 September 2017 / Published online: 11 September 2017

(C) The Author(s) 2017. This article is an open access publication

\begin{abstract}
Atmospheric aerosol optical depth (AOD) plays an important role in radiation modeling and partly determines the accuracy of estimated downward surface shortwave radiation (DSSR). In this study, Iqbal's model C was used to estimate DSSR under cloud-free conditions over the Koohin and Chitgar sites in Tehran, Iran; the estimated DSSR was based on (1) our proposed hybrid modeling scheme where the AOD is retrieved using the Simplified Aerosol Retrieval Algorithm (SARA), ground-based measurements at the AERONET site in Zanjan and (2) the AOD from the Terra MODerateresolution Imaging Spectroradiometer (MODIS) sensor. Several other Terra MODIS land and atmospheric products were also used as input data, including geolocation properties, water vapor, total ozone, surface reflectance, and top-ofatmosphere (TOA) radiance. SARA-based DSSR and MODIS-based DSSR were evaluated with ground-based DSSR measurements at the Koohin and Chitgar sites in 2011 and 2013, respectively; the averaged statistics for SARA-based DSSR $\left[R^{2} \approx 0.95, \mathrm{RMSE} \approx 22 \mathrm{~W} / \mathrm{m}^{2}(2.5 \%\right.$ mean value), and bias $\left.\approx 3 \mathrm{~W} / \mathrm{m}^{2}\right]$ were stronger than those for MODIS-based DSSR $\left[R^{2} \approx 0.79\right.$, RMSE $\approx 51 \mathrm{~W} / \mathrm{m}^{2}$ (5.8\% mean value), and bias $\left.\approx 34 \mathrm{~W} / \mathrm{m}^{2}\right]$. These results show that the proposed hybrid scheme can be used at regional to global scales under the assumption of future access to spatially distributed AERONET sites. Additionally, the robustness of this modeling scheme was exemplified by estimating the
\end{abstract}

Per Schubert

per.schubert@mah.se

1 Department of Photogrammetry and Remote Sensing, Faculty of Geodesy \& Geomatics Engineering, K. N. Toosi University of Technology, Tehran 19967-15433, Iran

2 Department of Science, Environment, and Society, Faculty of Education and Society, Malmö University, 20506 Malmö, Sweden aerosol radiative forcing (ARF) during a dust storm in Southwest Asia. The results were comparable to those of previous studies and showed the strength of our modeling scheme.

Keywords Downward surface shortwave radiation · Aerosol optical depth $\cdot$ MODIS $\cdot$ Aerosol radiative forcing $\cdot$ Dust storm

\section{Introduction}

Net surface shortwave radiation (NSSR) is defined as the difference between the total downward and upward shortwave radiation at the earth's surface in the 300-3000-nm region. As a main component of NSSR, the downward surface shortwave radiation (DSSR) controls the energy exchange between the atmosphere and land/ocean surfaces and significantly affects climate forming and change (Huang et al. 2012; Ma and Pinker 2012). Estimation of DSSR with high spatial and temporal resolution is needed for modeling and planning purposes in various areas such as agriculture, forestry, oceanography, meteorology, and climatology. DSSR is also used as input for quantifying evapotranspiration, which is a major input in soil water balance analyses (Carrer et al. 2012; Sellers et al. 1997; Sellers et al. 1996). Moreover, DSSR is a key factor for the determination of the best location for solar energy systems that focus on both concentrating photovoltaics and concentrating solar thermal systems.

Station-based measurements of DSSR are confined to specific locations, whereas remote sensing is used to retrieve data with local to global coverage (Liang 2004). Therefore, many broadband models have been built to estimate DSSR from remote sensing data, particularly from the MODerateresolution Imaging Spectroradiometer (MODIS) on the Terra and Aqua platforms and various other sensors on 
geostationary satellites. The broadband models that simulate the direct interaction between solar radiation and the atmosphere (including absorption by water vapor, gas, and ozone as well as absorption and scattering by aerosols) may be more suitable for multispectral sensors such as MODIS, which provide several atmospheric and land surface data products. MODIS data products have temporal resolutions of 1 day to 1 year and spatial resolutions such as $1 \mathrm{~km}$ (e.g., geolocation properties, surface reflectance, and water vapor) and $5 \mathrm{~km}$ (e.g., ozone amount), which are appropriate for mapping landscapes from the regional to global scale (MODIS 2016). Many algorithms that do not require such heavy computational power and detailed inputs as the radiative transfer models have been developed to estimate DSSR based on MODIS products (Bisht et al. 2005; Chen et al. 2012, 2014; Huang et al. 2012; Niu and Pinker 2015; Ryu et al. 2008; Wang et al. 2012).

Recent studies have shown that the accuracies of existing DSSR maps are not always satisfactory (Gueymard 2012; Suri et al. 2009). Moreover, it has been found that much of these uncertainties could be explained by inaccurate aerosol data used to model DSSR for cloud-free (clear-sky) conditions (Castelli et al. 2014; Gueymard 2011). Most current research in the estimation of solar radiation uses atmospheric aerosol information provided from chemical transport models that use data assimilation systems; the aerosol data may have coarse spatial resolution and may not be suitable for applications at scales between 1 and $10 \mathrm{~km}$ (Kim and Liang 2010). Recent land surface and climate models require a $10 \mathrm{~km}$ or finer spatial resolution (Bromwich et al. 2005; Kustas et al. 2004; Li et al. 2008). Various algorithms have been developed to estimate the AOD and to infer dust mass loading using remote sensing techniques at various spatial resolutions. MODIS Level 2 (L2) AOD has a spatial resolution of $10 \mathrm{~km}$ and provides aerosol properties from the Dark Target (DT) (Levy et al. 2007) and Deep Blue (DB) (Hsu et al. 2004) algorithms. The DT algorithm overestimates the AOD over bright surfaces and underestimates the AOD over unusually dark surfaces under clear atmospheric conditions (Levy et al. 2010). Moreover, the DT algorithm is unable to estimate the AOD under turbid conditions because of its limitation of DT selection criteria and thus produces many missing pixels (Bilal et al. 2013). The DB algorithm has fewer missing pixels because of its ability to estimate the AOD over bright surfaces; however, the estimated AOD still has low accuracy with considerable underestimation, especially under dusty conditions (Bilal et al. 2014). The MODIS Level 3 (L3) AOD consists of a spatial aggregation of MODIS L2 AODs into a regular grid with a spatial resolution of $1^{\circ}$ (Hubanks et al. 2008). Fewer missing pixels are found in MODIS L3 AOD, although the spatial resolution is coarse. The abovementioned problems would affect the estimates and make it difficult to obtain accurate DSSR at high spatial resolution under low and high aerosol loadings, particularly during dust storms. Therefore, the use of AOD data with higher spatiotemporal resolutions is necessary to reduce uncertainties in the estimation of the DSSR under clear and turbid atmospheric conditions.

Bilal et al. (2013) have recently developed the effective Simplified Aerosol Retrieval Algorithm (SARA) for higher spatiotemporal resolution AOD. SARA uses MODIS radiance and surface reflectance data, and single scattering albedo and asymmetry factor extracted from AERONET site. Bilal et al. (2013) have evaluated SARA over Hong Kong and showed that SARA better represents aerosol conditions than MODIS L2 AOD Collection 5 (C5). SARA also performed better than previous higher resolution algorithms, which were also studied over Hong Kong under low and high aerosol loadings (Bilal et al. 2013; Chengcai et al. 2005; Wong et al. 2011). In addition to SARA's performance, it is able to retrieve AOD for a particular location more frequently than the MODIS DT algorithm because it considers all cloud-free pixels, as opposed to the selection of dark-target pixels by the DT algorithm (Bilal et al. 2014). Bilal et al. (2014) also investigated the robustness and accuracy of SARA under a severe dust storm in Beijing on 17th April 2006; their results showed that the SARA AOD had higher accuracy and reliability than the MODIS L2 AOD. The SARA algorithm has been further validated for haze pollution over land using MODIS data (Bilal and Nichol 2015), and over coastal water surfaces using VIIRS data (Bilal et al. 2017).

Iqbal's broadband model C (Iqbal 1983) was used to calculate the DSSR from various land and atmospheric data from Terra MODIS in northern Iran, including the Koohin and Chitgar sites in 2011 and 2013, respectively (see Table 1). Instead of using the coarse spatial resolution and low accuracy of the MODIS AOD product, SARA was used to retrieve AOD at $1 \mathrm{~km}$ resolution, and the SARA AOD was then used to estimate SARAbased DSSR at the study sites. Therefore, a hybrid scheme was developed in this study to estimate SARA-based DSSR at $1 \mathrm{~km}$ resolution using MODIS data. For comparison purposes, MODIS L3 AOD was also used to estimate MODIS-based DSSR at the study sites. Finally, we attempted to estimate the radiative effect of aerosols (called aerosol radiative forcing, ARF) using a proposed hybrid scheme during a dust storm in Southwest Asia, and we tried to understand the radiative implications of dust in the shortwave region.

The aim of this study was to evaluate the proposed hybrid modeling scheme for estimation of high-resolution DSSR at two distinct sites in northern Iran and then to exemplify its usefulness by assessing ARF during a dust storm event. To achieve this aim, the objectives were as follows:

- estimate the DSSR with Iqbal's model C based on the SARA AOD and MODIS L3 AOD and evaluate the 
Table 1 Information on the Koohin and Chitgar eddy covariance sites and the IASBS AERONET sun photometer site

\begin{tabular}{llllll}
\hline Sites & Name & Latitude & Longitude & Elevation $(\mathrm{m})$ & Instrument \\
\hline Eddy covariance & Koohin & $36.33^{\circ} \mathrm{N}$ & $49.71^{\circ} \mathrm{E}$ & 1448 & CMP6 pyranometer \\
& Chitgar & $35.76^{\circ} \mathrm{N}$ & $51.20^{\circ} \mathrm{E}$ & 1305 & \\
Sun photometer & IASBS & $36.70^{\circ} \mathrm{N}$ & $48.50^{\circ} \mathrm{E}$ & 1805 & CIMEL sun photometer \\
\hline
\end{tabular}

SARA-based and MODIS-based DSSR with pyranometer measurements; and

- assess the ARF upon DSSR and NSSR by applying the modeling hybrid scheme to a dust storm event.

\section{Materials and methods}

\section{Study sites and field measurements}

The I. R. of the Iran Meteorological Office (IRIMO) conducted a program that measured various meteorological and surface variables over the North of Iran (IRIMO 2016). In this study, we used data from two eddy covariance sites, the Koohin and Chitgar sites located in Qazvin and Tehran, that provide continuous measurements of DSSR (Fig. 1). Data acquired in 2011 at the Koohin site and 2013 at the Chitgar site were used for validating the DSSR estimates. Two Kipp and Zonen CMP6 pyranometers at the height of $1.5 \mathrm{~m}$ above the ground were used to measure DSSRs at the study sites (Table 1). Data were quality controlled using SPSS software, and data outside one standard deviation were considered outliers. Ground measurements were recorded every $10 \mathrm{~min}$ at the ground stations. The measurement data from both Koohin and Chitgar were aggregated to 30-min intervals for

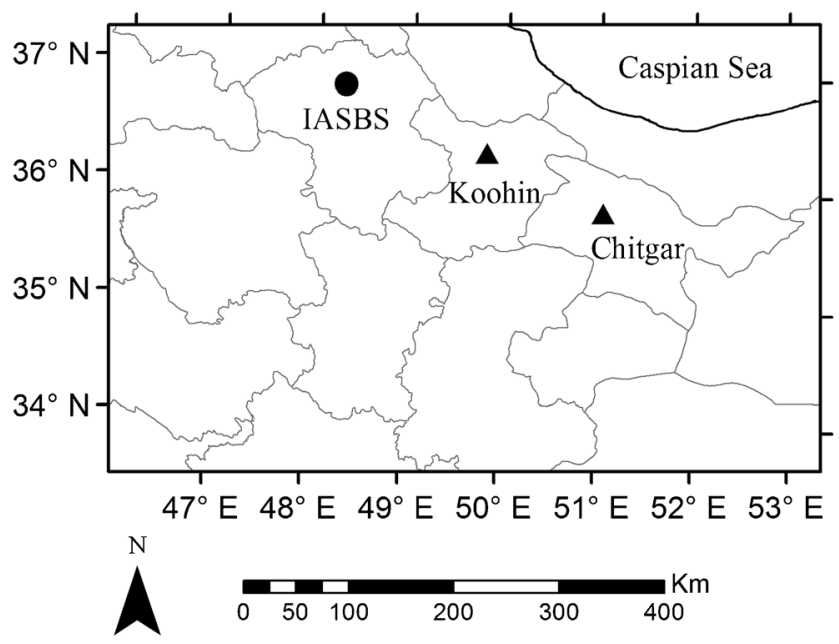

Fig. 1 The Koohin and Chitgar eddy covariance sites (triangles) and the IASBS AERONET sun photometer site (circle) comparison with the estimates of DSSR presented in the "Results" section.

The IASBS AERONET site is located in Zanjan (Fig. 1 and Table 1) and was also used to obtain cloud-screened level 1.5 Version 2 AOD data for the study days. These data were also averaged for $\pm 30 \mathrm{~min}$ around the Terra satellite overpass time and were used to calculate the single scattering albedo and the asymmetry factor by SARA over the Qazvin Koohin and Tehran Chitgar sites.

Additionally, visibility data were obtained from an IRIMO meteorological station at the Mehrabad Airport, located only $13 \mathrm{~km}$ from the Chitgar site $\left(35.68^{\circ} \mathrm{N}, 51.31^{\circ} \mathrm{E}\right)$ (http://www. irimo.ir/eng/wd/720-Products-Services.html). An observer measures these visibility data manually every $3 \mathrm{~h}$. Normally, visibility did not change much during a day, and data were therefore averaged for each day. An equation provided by Vermote et al. (2002) was then used to retrieve the visibilitybased AOD from daily visibility data.

\section{MODIS sensor data}

The Terra MODIS level 1 top-of-atmosphere (TOA) radiance product (MOD02), geolocation product (MOD03), level 2 land surface reflectance product (MOD09), level 2 land surface temperature (LST) product (MOD11), level 2 water vapor product (MOD05), level 2 atmospheric profiles product (MOD07), and level 3 atmospheric product (MOD08) were obtained from the Goddard Space Flight Center (GSFC) Level-1 and Atmosphere Archive and Distribution System (LAADS) (http://ladsweb.nascom.nasa.gov). The various MODIS data products and parameters used, along with their spatial resolutions, are summarized in Table 2. The schemes presented in this paper were run at a resolution of $1 \mathrm{~km}$ on a regular latitude-longitude grid. However, even if the estimated DSSRs are at $1 \mathrm{~km}$ resolution, some of the input data are only at the nominal $1 \mathrm{~km}$ resolution, which is different from the real resolution. In addition, the level 2 atmospheric profiles product (MOD07) and the level 3 atmospheric product (MOD08) have $5 \mathrm{~km}$ and $1^{\circ}$ resolutions, respectively, and were therefore resampled to the $1 \mathrm{~km}$ resolution of the other products.

Table 3 lists the number of acceptable cloud-free days over the study sites, including the Koohin and Chitgar sites during June-October 2011 and June-October 2013, respectively. Twenty five and 19 cloud-free days at the Koohin and Chitgar sites, respectively, were selected for the LST product. 
Table 2 Summary of the MODIS data products used in this study

\begin{tabular}{lllll}
\hline MODIS product & Short name & Resolution & Parameters used & Model or purpose \\
\hline Radiance & MOD02 & $1 \mathrm{~km}$ & TOA radiance in the green band & SARA \\
Geolocation & MOD03 & $1 \mathrm{~km}$ & Height, zenith angles, azimuth angles & SARA/Iqbal's model C \\
Water vapor & MOD05 & $1 \mathrm{~km}$ & Water vapor amount & Iqbal's model C \\
Atmospheric & MOD07 & $5 \mathrm{~km}$ & Ozone amount & Iqbal's model C \\
Atmospheric & MOD08 & $1^{\circ}$ & Aerosol optical depth & Iqbal's model C \\
Surface reflectance & MOD09 & $1 \mathrm{~km}$ & Surface reflectance in the green band & SARA \\
Land surface temperature & MOD11 & $1 \mathrm{~km}$ & Surface temperature & Identifying cloud-free days \\
\hline
\end{tabular}

The LST data product is only available for cloud-free pixels, and pixels in the LST product for which land surface temperature was available thus served as an indicator of the cloud cover over the study site.

\section{Retrieval of AOD using SARA}

The SARA algorithm (Eq. (1)) is based on real viewing geometry and encompasses a wide range of aerosol conditions and types (Bilal and Nichol 2015; Bilal et al. 2013, 2014). SARA has three assumptions: (1) the surface is Lambertian, (2) single scattering approximation, and (3) the single scattering albedo and the asymmetry factor do not vary spatially over the region on the day of retrieval. The SARA algorithm is expressed as:

$$
\begin{aligned}
\tau_{\mathrm{a}, \lambda}= & \frac{4 \mu_{\mathrm{s}} \mu_{\mathrm{v}}}{\omega_{0} P_{\mathrm{a}\left(\theta_{\mathrm{s}}, \theta_{v}, \phi\right)}}\left[\rho_{\mathrm{TOA}\left(\lambda, \theta_{\mathrm{s}}, \theta_{v}, \phi\right)}-\rho_{\mathrm{Ray}\left(\lambda, \theta_{\mathrm{s}}, \theta_{\mathrm{v}}, \phi\right)}\right. \\
& \left.-\frac{e^{-\left(\tau_{\mathrm{R}}+\tau_{\mathrm{a}, \lambda}\right) / \mu_{\mathrm{s}}} e^{-\left(\tau_{\mathrm{R}}+\tau_{\mathrm{a}, \lambda}\right) / \mu_{\mathrm{v}}} \rho_{\mathrm{s}\left(\lambda, \theta_{\mathrm{s}}, \theta_{\mathrm{v}}, \phi\right)}}{1-\rho_{\mathrm{s}\left(\lambda, \theta_{\mathrm{s}}, \theta_{v}, \phi\right)}\left(0.92 \tau_{\mathrm{R}}+(1-g) \tau_{\mathrm{a}, \lambda}\right) \exp \left[-\left(\tau_{\mathrm{R}}+\tau_{\mathrm{a}, \lambda}\right)\right]}\right]
\end{aligned}
$$

where $\tau_{\mathrm{a}, \lambda}=$ spectral aerosol optical depth, $\tau_{\mathrm{R}}=$ Rayleigh optical depth, $\rho_{\text {TOA }}=$ TOA reflectance, $\rho_{\mathrm{s}}=$ surface reflectance, $\rho_{\text {Ray }}=$ Rayleigh reflectance, $P_{\mathrm{a}}=$ aerosol phase function, $\omega_{\mathrm{o}}=$ single scattering albedo, $g=$ asymmetry factor, $\mu_{\mathrm{s}}=$ cosine of solar zenith angle, $\mu_{\mathrm{v}}=$ cosine of sensor zenith angle, $\theta_{\mathrm{s}}=$ solar zenith angle, $\theta_{\mathrm{v}}=$ view zenith angle, $\phi=$ relative azimuth angle, and $\lambda=$ wavelength (here $\lambda=550 \mathrm{~nm}$, the green wavelength of MODIS). The Rayleigh optical depth mainly depends on the ambient pressure and ground elevation and can be calculated using an equation suggested in Liang (2004). Rayleigh reflectance depends on the determination of the Rayleigh phase function (Lado-Bordowsky and Naour 1997; Liang 2004) and Rayleigh optical depth. The aerosol phase function represents the angular distribution of light scattered by particles, and the aerosol phase function is determined by the single-term Henyey-Greenstein method (Rahman et al. 1993). The TOA reflectance is a function of the TOA radiance, SZA, earth-sun distance in astronomical units and mean solar exoatmospheric radiation and can be estimated using Eq. (2) (Allen et al. 2007):

$\rho_{\mathrm{TOA}(\lambda)}=\frac{\pi L_{\mathrm{TOA}(\lambda)} d^{2}}{E S U N_{\lambda} \mu_{\mathrm{s}}}$

where $L_{\mathrm{TOA}(\lambda)}=$ satellite-received TOA spectral radiance, $E S U N_{\lambda}=$ mean solar exoatmospheric radiation as a function of MODIS band wavelengths (Tasumi et al. 2008), and $d=$ the earth-sun distance in astronomical units. The detailed calculation procedures follow the equations in Bilal et al. (2013); they are not repeated here but can be found in the original documents.

Although $\omega_{\mathrm{o}}$ and $g$ have very small changes during a day for clear-sky conditions, both may show relatively large changes under turbid conditions. The results presented in Bilal et al. (2013) suggested that AOD retrieved by SARA is

Table 3 Accepted cloud-free days for the MODIS instrument on-board the Terra satellite for the Koohin site in 2011 and the Chitgar site in 2013

\begin{tabular}{lll}
\hline Months & Julian days for Koohin & Julian days for Chitgar \\
\hline June & 176,180 & 157,173 \\
July & $185,197,200,205,209,212$ & $182,183,185,187,189,194,198,203,205$ \\
August & 215,233 & 230,237 \\
September & $244,246,247,248,249,251,253,256,257,260,272$ & $251,258,262,265,269,271$ \\
October & $276,279,283,297$ & - \\
\hline
\end{tabular}


more sensitive to $\rho_{\mathrm{s}}$ than to $g$ and $\omega_{\mathrm{o}}$ under clear-sky conditions. Additionally, Bilal et al. (2014) considered a wider range of aerosol types $\left(\omega_{\mathrm{o}}=0.30-1.0, g=0.0-1.0\right)$ to retrieve SARA AOD during a dust storm. The results indicated that the assumptions of aerosol conditions and types and the surface reflectance used in SARA are reasonable. On the other hand, Iqbal's model C used to estimate DSSR is relatively insensitive to small changes in these parameters. Therefore, we assumed in the present research that $\omega_{\mathrm{o}}$ and $g$ were constant for a particular day over the studied sites.

Daily values of $\omega_{\mathrm{o}}$ and $g$ for all days for which SARA AOD was retrieved were determined from matching SARA AODs as a function of $\omega_{\mathrm{o}}$ and $g$, and the averaged AOD from the IASBS site was obtained within \pm 30 min of the Terra satellite local overpass time. This was empirically accomplished using the fixed point iteration (FPI) method (Kelley 1995) and by varying the values of $\omega_{\mathrm{o}}$ and $g$ until a match was obtained. Then, $\omega_{\mathrm{o}}$ and $g$, together with the MODIS green TOA reflectance and surface reflectance, were used to estimate the $1 \mathrm{~km}$ AOD over the Koohin and Chitgar sites at Terra satellite overpass time. The retrieved SARA AOD was then extracted and averaged for a $3 \mathrm{~km} \times 3 \mathrm{~km}$ spatial subset region cantered on both sites (Ichoku et al. 2002).

\section{Retrieval of the AOD using visibility measurements}

The recorded visibility at the Mehrabad Airport was converted to AOD using the Vermote et al.'s (2002) formula (Eq. (3)):

$V=3.9449 /\left(A O D_{550}-0.08498\right)$

where $V$ is the visibility in $\mathrm{km}$ and $A O D_{550}$ is AOD at the 550$\mathrm{nm}$ wavelength. The equation is not valid for $\mathrm{AOD} \leq 0.08498$. The estimated daily AOD was then compared with SARA AOD and MODIS L3 AOD at the Chitgar site.

\section{Retrieval of DSSR using MODIS data}

Iqbal's model C was used to estimate the DSSR using MODIS land and atmospheric products (Eqs. (4)-(7)). See Iqbal (1983) for a more detailed description of the algorithm. DSSR consists of two components, direct and diffuse. Direct downward shortwave surface radiation $\left(I_{d i r}\right)$ can be expressed as:

$I_{\mathrm{dir}}=I_{0} \cos (\theta) \times 0.9751 \times T_{\mathrm{R}} T_{\mathrm{G}} T_{\mathrm{O}} T_{\mathrm{W}} T_{\mathrm{A}}$

where $I_{0}$ is the extra-terrestrial solar radiation corrected for the earth-sun distance, $\theta$ is the SZA, $T_{\mathrm{R}}$ is the transmittance of Rayleigh scattering, $T_{\mathrm{G}}$ is the transmittance of absorbance of uniformly mixed gases (carbon dioxide and oxygen), $T_{\mathrm{o}}$ is the transmittance of ozone absorbance, $T_{\mathrm{w}}$ is the transmittance of water vapor absorption, and $T_{\mathrm{A}}$ is the transmittance of aerosol absorbance and scattering. Diffuse downward shortwave surface radiation $\left(I_{\mathrm{dif}}\right)$ can be expressed as:

$$
\begin{aligned}
I_{\mathrm{dif}}= & I_{\mathrm{as}}+\alpha r_{\mathrm{s}}\left(I_{\mathrm{dir}}+I_{\mathrm{as}}\right) /\left(1-\alpha r_{\mathrm{s}}\right) \\
I_{\mathrm{as}}= & I_{0} \cos (\theta) \times 0.79 \times T_{\mathrm{G}} T_{\mathrm{O}} T_{\mathrm{W}} T_{\mathrm{AA}} \\
& \times \frac{0.5\left(1-T_{\mathrm{R}}\right)+B_{\mathrm{a}}\left(1-T_{\mathrm{AS}}\right)}{1-m_{\mathrm{a}}+m_{\mathrm{a}}{ }^{1.02}}
\end{aligned}
$$

where $I_{\text {as }}$ is diffuse downward shortwave surface radiation from Rayleigh and aerosol scattering, $T_{\mathrm{AA}}$ is the transmittance of aerosol absorbance, $T_{\mathrm{AS}}$ is the transmittance of aerosol scattering, $B_{\mathrm{a}}$ is the ratio of the forward-scattered radiation to the total radiation scattered by aerosols and treated as the constant 0.84 (Annear and Wells 2007), $m_{\mathrm{a}}$ is the pressure-corrected air mass, $\alpha$ is the ground albedo, and $r_{\mathrm{s}}$ is the atmospheric albedo. Then, the total DSSR (direct plus diffuse) can be expressed by Eq. (7).

$D S S R=I_{\mathrm{dir}}+I_{\mathrm{dif}}=\frac{I_{\mathrm{dir}}+I_{\mathrm{as}}}{1-\alpha r_{\mathrm{s}}}$

MODIS LST is available only for cloud-free pixels, and pixels for which LST is available were thus used as indicators of cloud-free conditions. For cloud-free pixels, the SARA AOD was first retrieved by SARA using the single scattering albedo and the asymmetry factor obtained from the IASBS AERONET site and the geolocation properties, TOA radiance, and surface reflectance from MOD03, MOD02, and MOD09, respectively. Then, the retrieved SARA AOD was used as input to Iqbal's model $\mathrm{C}$ along with the SZA, water vapor amount, and ozone amount extracted from MOD03, MOD05, and MOD07 to estimate the SARA-based DSSR at the study sites. For comparison, MODIS L3 AOD together with the MODIS data products for SZA, water vapor amount, and ozone amount were also used to estimate the MODIS-based DSSR at the study sites. SARA-based DSSR estimates obtained from our hybrid scheme and MODIS-based DSSR were then extracted and averaged for a $3 \mathrm{~km} \times 3 \mathrm{~km}$ spatial subset region centered on the Koohin and Chitgar sites at the Terra satellite overpass times. The framework of the method is summarized in the flowchart shown in Fig. 2.

The following statistical measures were used to evaluate SARA-based and MODIS-based DSSR against groundbased measurements of DSSR at the selected sites:

$$
\begin{aligned}
& R^{2}=\sum_{i=1}^{n}\left(E_{i}-\bar{E}\right)\left(O_{i}-\bar{O}\right) / \sum_{i=1}^{n}\left(E_{i}-\bar{E}\right)^{2} \sum_{i=1}^{n}\left(O_{i}-\bar{O}\right)^{2} \\
& R M S E=\left[\frac{1}{n} \sum_{i=1}^{n}\left(E_{i}-O_{i}\right)^{2}\right]^{1 / 2} \\
& M A P E=\frac{100}{n} \sum_{i=1}^{n} \frac{\left|E_{i}-O_{i}\right|}{\bar{O}}
\end{aligned}
$$


Fig. 2 Framework of the SARAbased DSSR obtained from our hybrid scheme and MODISbased DSSR. The shaded area indicates retrieval of the AOD using SARA, where $\omega_{\mathrm{o}}$ is the single scattering albedo and $g$ is the asymmetry factor. The definition of each product in the flowchart can be found in Table 2

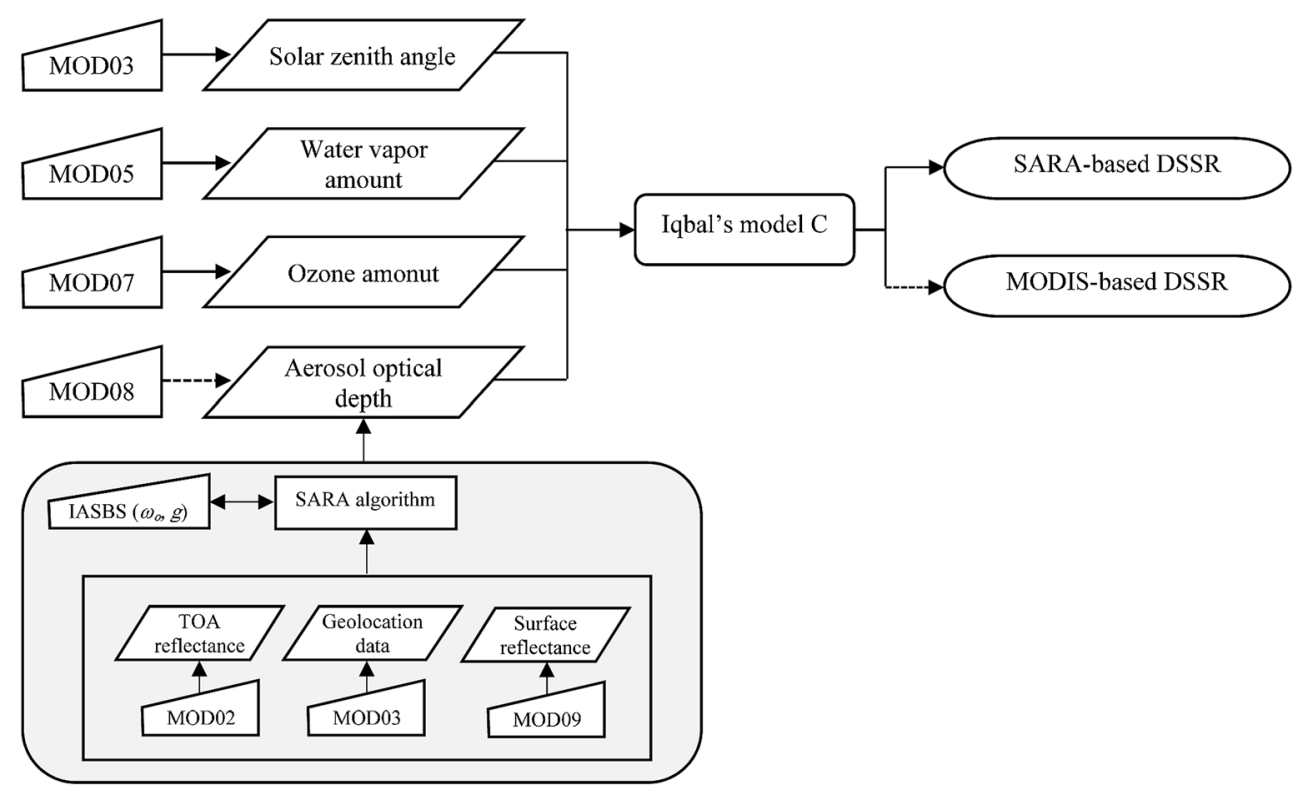

Bias $=\frac{1}{n} \sum_{i=1}^{n}\left(E_{i}-O_{i}\right)$

where $R^{2}, R M S E, M A P E$, and Bias are the coefficient of determination, root mean square error, mean absolute percent error, and bias, respectively. $E$ and $O$ are the estimated and observed DSSR, and $\bar{E}$ and $\bar{O}$ are the mean values of estimated and observed DSSR.

\section{Retrieval of aerosol radiative forcing during a dust storm event}

Southwest Asia, including, e.g., Iran, the Persian Gulf, Iraq, and Saudi Arabia, is a hot-spot region that has reported the highest frequency of dust storms (Furman and Kutiel 2003). Dust storms in these regions, especially in Southwest Iran, are more frequent in spring and summer than in autumn and winter. On 4th July 2009, a massive dust storm had persisted over Iraq for a week when it began to spread towards the east and southeast, over Iran and the Persian Gulf (NASA 2016).

This dust storm was used to exemplify the applicability of our proposed hybrid scheme for SARA-based DSSR; Ahvaz in Iran, Persian Gulf in Iran, Al Basrah in Iraq, and Kuwait City in Kuwait were chosen as study sites, and our scheme was used to assess the ARF upon DSSR ( $\left.\mathrm{ARF}_{\mathrm{DSSR}}\right)$ and NSSR ( $\mathrm{ARF}_{\mathrm{NSSR}}$ ) for 4th July and 9th July. According to measurements made at the Kuwait University AERONET site, 4th July had the largest AOD, and 9th July in 2009 had the lowest AOD among the observation days (Fig. 3).

Therefore, we selected 4th July as the dusty day and 9th July as the non-dusty day. AOD data for Kuwait City were obtained directly from the Kuwait University AERONET site, whereas SARA was used for the other sites. For all four sites,
Iqbal's model C was used to calculate SARA-based DSSR. DSSR was then averaged for the dusty and non-dusty days using a sinusoidal model proposed by Bisht et al. (2005). Finally, daily average $\mathrm{ARF}_{\mathrm{DSSR}}$ was calculated by Eq. (12):

$A R F_{D S S R}=D S S R-D S S R^{\mathrm{O}}$

where daily average $A R F_{\mathrm{DSSR}}$ is defined as the difference between daily average $D S S R$ with aerosols and daily average $D S S R^{\mathrm{O}}$ without aerosols. $D S S R^{\mathrm{O}}$ was calculated for 4th July and 9th July under the assumption that $A O D=0.1$ (aerosolfree days). Surface albedo can be used to estimate ARF $_{\text {NSSR }}$. The surface albedo was derived from the MODIS bidirectional reflectance distribution function/albedo product (Moody et al. 2005). MODIS provides both black-sky albedo (BSA) (direct reflectance) and white-sky albedo (WSA) (bihemispherical reflectance) for seven spectral bands $(0.470$, $0.555,0.659,0.858,1.240,1.640$, and $2.100 \mu \mathrm{m})$ as well as for three broadbands $(0.4-0.7,0.7-4.0$, and $0.3-4.0 \mu \mathrm{m})$ at $1 \mathrm{~km}$ spatial resolution (Schaaf et al. 2002). Surface albedo was then calculated from BSA and WSA for the dusty and non-dusty days using Eq. (13):

Surface albedo $(\alpha)=W S A * D S F+B S A(1-D S F)$

where $D S F$ is the diffuse sky fraction, which is a function of aerosol loading and SZA. The retrieved SARA AOD was used to derive the DSF using a look-up table provided by the MODIS land team (Lucht et al. 2000). Daily average $A R F_{\text {NSSR }}$ is defined as the difference between the daily average NSSR with aerosols and the daily average NSSR without 
Fig. 3 Variability of mean daily AOD data during the dust storm at the Kuwait University AERONET site in July 2009

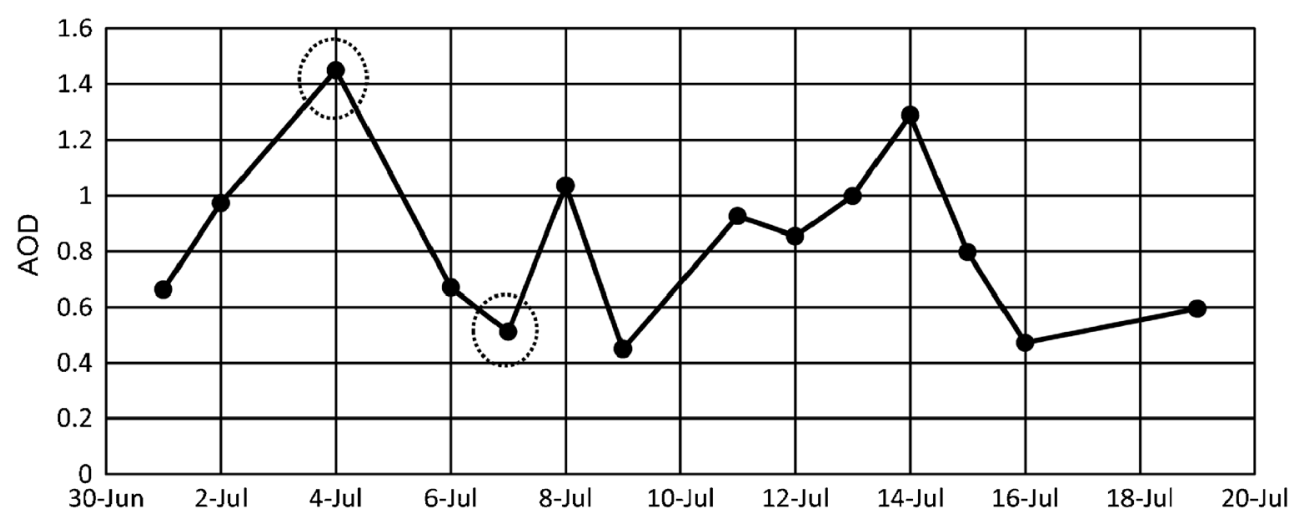

aerosols, $N S S R^{\mathrm{O}}$, and can also be calculated from the surface albedo and daily average $A R F_{\mathrm{DSSR}}$ (Eq. (14)):

$A R F_{N S S R}=(1-\alpha) A R F_{D S S R}$

\section{Results}

\section{Comparison of estimated AODs at the Chitgar site}

Figure $4 \mathrm{a}, \mathrm{b}$ shows the comparisons between the SARA AOD and MODIS L3 AOD at the Chitgar site with the visibility AOD at Mehrabad Airport site, which is only $13 \mathrm{~km}$ away from the Chitgar site. The SARA AOD is in good agreement with the visibility AOD, whereas the MODIS L3 AOD seems to overestimate the AOD. We could expect the SARA AOD to be more accurate than the MODIS L3 AOD since more detailed land and atmospheric data have been used as inputs to SARA, i.e., higher resolution MODIS TOA reflectance and surface reflectance together with the IASBS single scattering albedo and the asymmetry factor. In comparison, the MODIS L3 AOD uses the DT algorithm, which works well only over densely vegetated ("dark") surfaces and overestimates AOD over bright surfaces $\left(\rho_{2.21} \mu \mathrm{m}\right.$ approaching 0.25$)$ (Levy et al. 2010). An average window of $3 \mathrm{~km} \times 3 \mathrm{~km}$ pixels over the Chitgar site was calculated and shows that the surroundings consist of bright surfaces $\left(\rho_{2.21} \mu \mathrm{m}\right.$ approaching 0.24$)$ that
Fig. 4 SARA AOD (solid line) (a) and MODIS L3 AOD (dotted line) (b) at the Chitgar site compared with visibility AOD (dashed line) at Mehrabad Airport for cloud-free days during JuneOctober 2013. Note: There are no values on Julian days 262 and 271 for MODIS L3 AOD and on Julian days 182, 230, 269, and 271 for visibility AOD
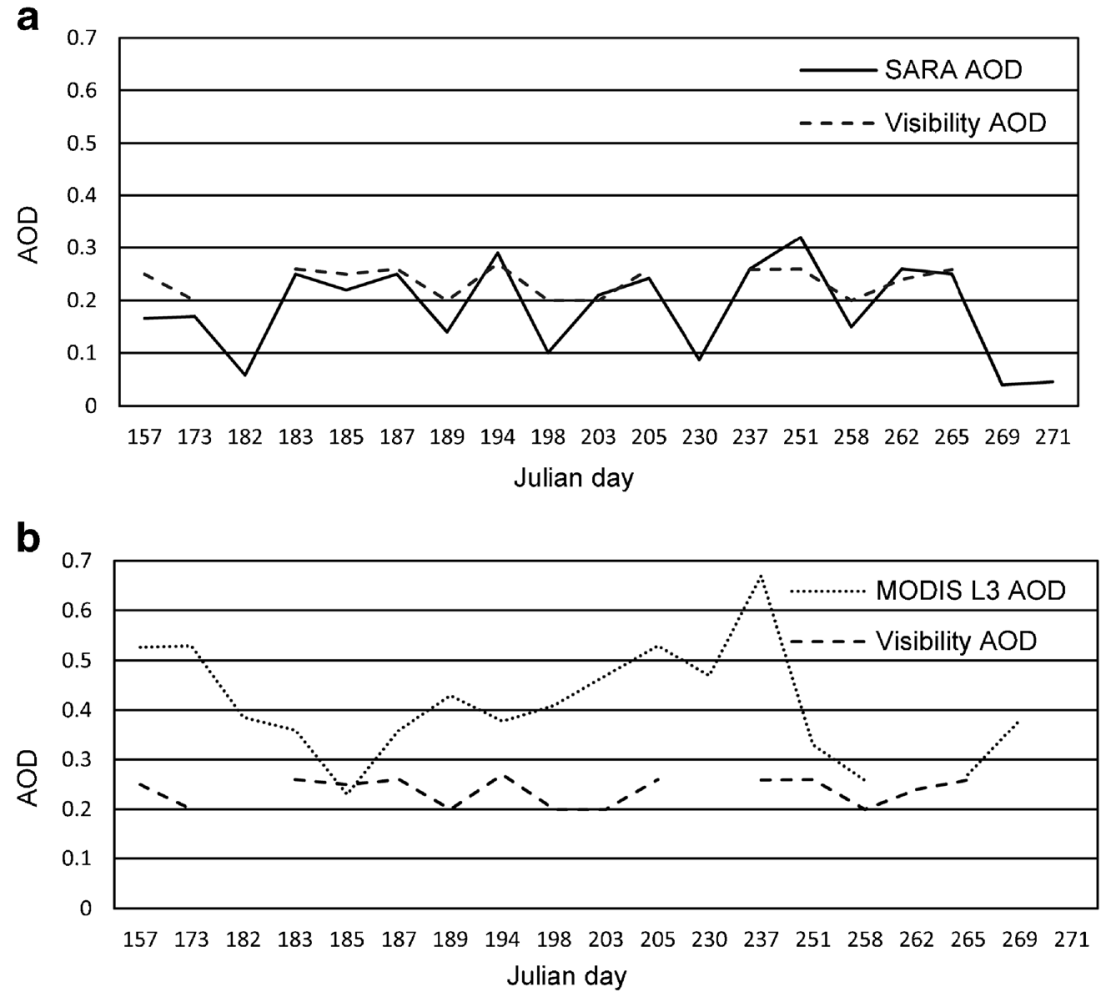
should generate overestimated AOD values. Additionally, SARA can estimate the AOD with a 1-km spatial resolution, in comparison to the $1^{\circ}$ MODIS L3 AOD. SARA is superior to the MODIS DT algorithm in resolution and accuracy and in its consideration of all cloud-free pixels. Therefore, the SARA AOD could be appropriate input data to estimate DSSR with $1 \mathrm{~km}$ resolution.

\section{Spatial representations of AOD over the North of Iran}

Figure 5a, b shows spatial SARA and MODIS L3 AOD representations over the North of Iran, including Zanjan (brown oval) and Tehran (black oval) and its surroundings on 6th June 2013. Spatial variations in AOD were obviously well captured by SARA AOD (see Fig. 5a), whereas MODIS L3 AOD has such coarse resolution that it was not able to represent these variations (see Fig. 5b). SARA AOD revealed a fairly high aerosol loading $(\sim 0.50)$ over the Namak Lake (red oval), which is a salt lake in Iran because of salt aerosols from dry parts of the lake and mineral dust aerosols from the Dasht-e Kavir, also known as Kavir-e Namak and the Great Salt Desert. However, MODIS L3 AOD was completely unable to represent this high aerosol loading because of missing pixels over the affected area (see Fig. 5b). Because of its higher spatial resolution, the SARA AOD could show detailed information on DSSR in the North of Iran, whereas the MODIS L3 AOD was unable to represent variations not only because of low resolution but also because of the effect of bright aerosols on the visible band thresholding, which resulted in missing data.

\section{Validation of estimated DSSRs}

Estimated DSSRs based on the scheme presented in the "Retrieval of DSSR using MODIS data" section were

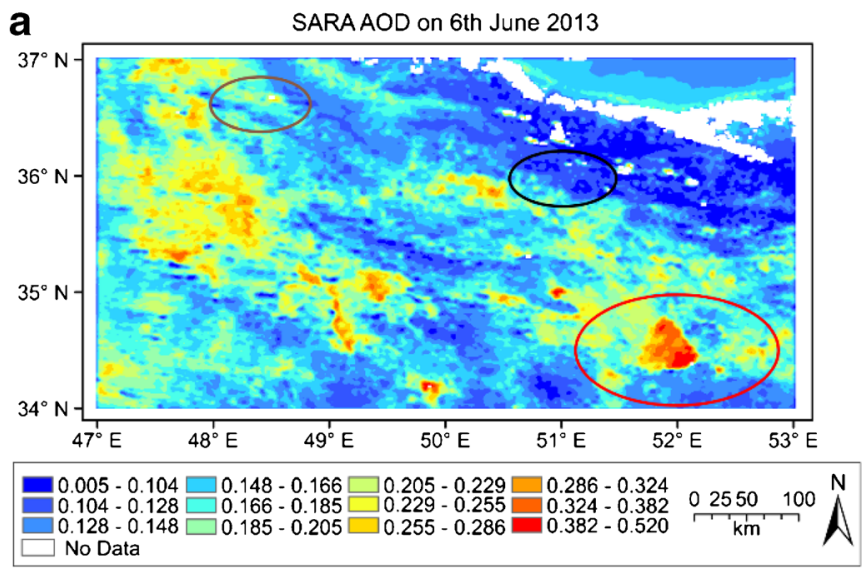

Fig. 5 Spatial patterns in the (a) SARA AOD and (b) MODIS L3 AOD on 6th June 2013 over the North of Iran, including Zanjan and the IASBS site (brown oval), Tehran and the Chitgar site (black oval) and Namak validated using the ground-based measurements recorded at the Koohin and Chitgar sites under cloud-free conditions. The modeling scheme was applied to 25 cloud-free days for the period June-October 2011 and 19 cloud-free days for the period June-October 2013 during MODIS overpasses at the Koohin and Chitgar sites, respectively. The distinction between cloud-free and cloudy days was made based on the MOD11 L2 data product that is available for only cloud-free pixels.

Figure 6 and Table 4 show the validations of SARA-based and MODIS-based DSSR against pyranometer measurements during the study days at the Koohin and Chitgar sites. The SARA-based DSSR resulted in $R^{2}$ s of 0.96 and 0.93 , RMSEs of 23.48 (2.8\% of mean value) and $20.40 \mathrm{~W} / \mathrm{m}^{2}(2.2 \%$ of mean value), biases of -2.92 and $3.00 \mathrm{~W} / \mathrm{m}^{2}$, and MAPEs of 2.37 and $1.83 \%$ at the Koohin and Chitgar sites, respectively (Fig. 6a1, a2). The MODIS-based DSSR resulted in $R^{2}$ s of 0.71 and 0.86 , RMSEs of 52.83 (6.3\% of mean value) and $49.93 \mathrm{~W} / \mathrm{m}^{2}$ ( $5.4 \%$ of mean value), biases of 24.05 and $43.59 \mathrm{~W} / \mathrm{m}^{2}$, and MAPEs of 4.81 and $5.11 \%$ at the Koohin and Chitgar sites, respectively (Fig. 6b1, b2).

From Table 4, it appears that the estimated DSSRs were relatively similar at the Koohin and Chitgar sites for both SARA-based and MODIS-based schemes. Compared with the MODIS-based DSSR, the estimated instantaneous SARA-based DSSR agreed well with ground-based measurements with very low bias at both sites. The computed average RMSE for SARA-based DSSR was 2.3 times smaller than that for MODIS-based DSSR, which indicates the high accuracy of the presented hybrid scheme at the study sites for the investigated days. This higher accuracy may be explained by use of SARA, which uses detailed properties of the land and atmosphere to retrieve the AOD. The RMSE of the MODISbased DSSR is close to the results found by Bisht et al. (2005), Wang et al. (2012), and Niu and Pinker (2015) when they

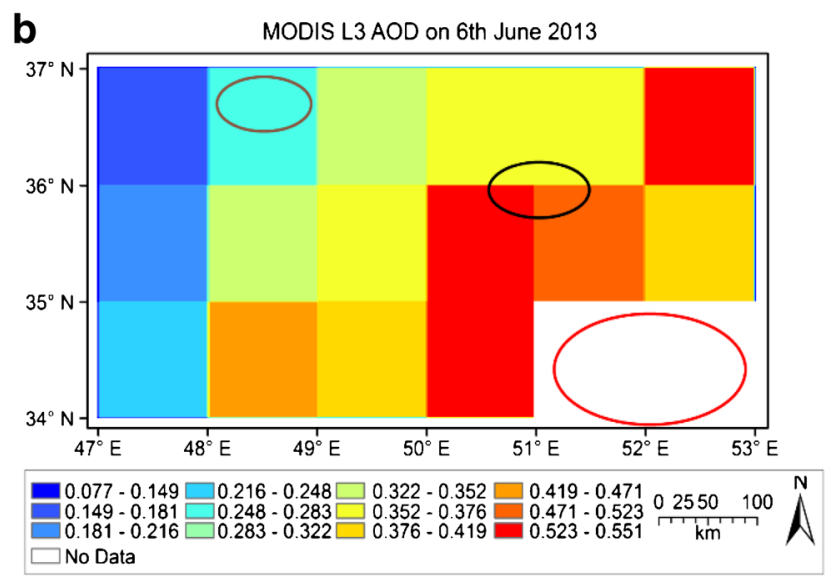

Lake (red oval). White color means no information because of cloud cover in the left map and no information because of missing values in the MODIS product in the right map 
Fig. 6 SARA-based (a1-a2) and MODIS-based (b1-b2) DSSR validations using ground-based measurements at the Koohin site in 2011 and the Chitgar site in 2013

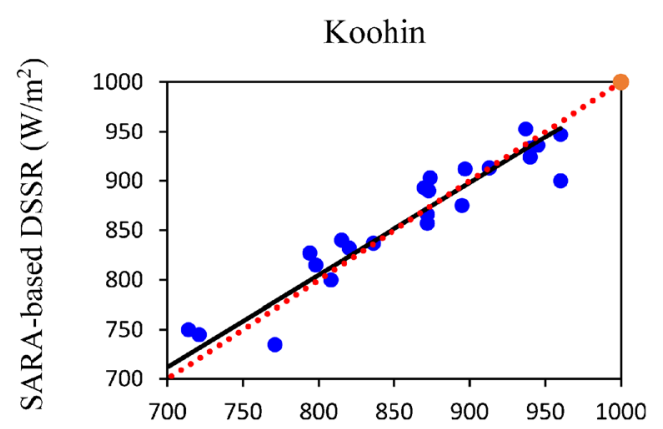

(a1)

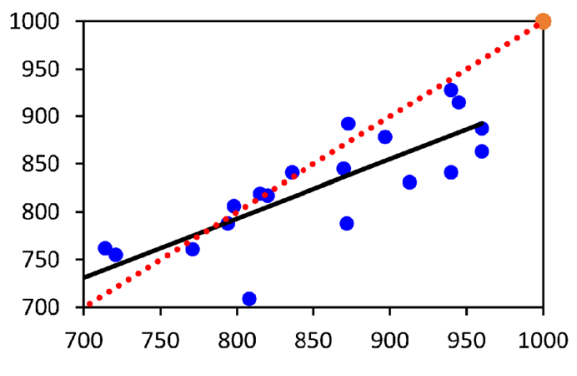

(b1)
Chitgar

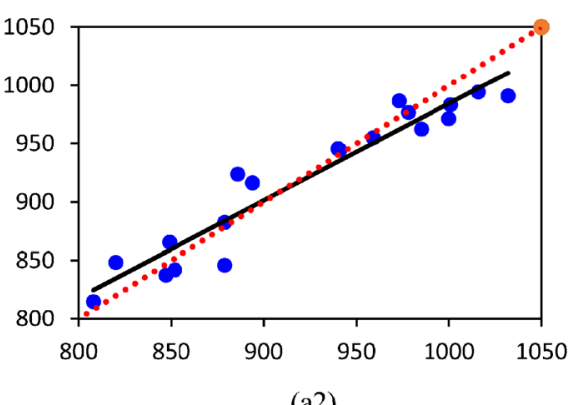

(a2)

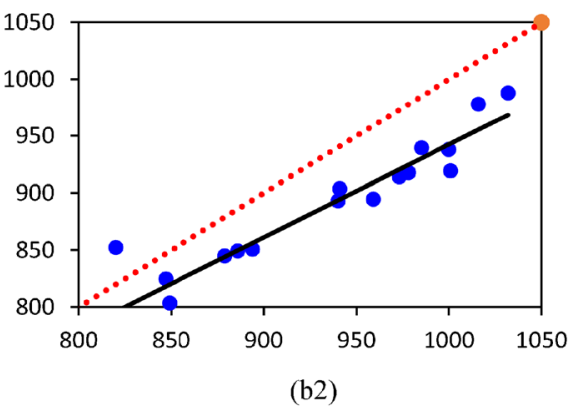

Ground-measured DSSR $\left(\mathrm{W} / \mathrm{m}^{2}\right)$

compare estimated DSSR using MODIS products with ground-based observations over the Southern Great Plains (SGP), Tibetan Plateau, and Arctic region, respectively. The retrieval algorithm of the MODIS atmospheric product provided relatively low accuracy when estimating the L3 AOD compared with the SARA AOD at the Chitgar site (as shown in "Comparison of estimated AODs at the Chitgar site" section). Therefore, the relatively large errors for MODIS-based DSSRs at the study sites may have been caused by the use of coarse-resolution L3 AOD data.

Spatial representations of the estimated DSSR over the North of Iran

Figure 7a, b shows spatial representations of the SARA-based and MODIS-based DSSR over the North of Iran, including Zanjan (brown oval) and Tehran (black oval) and its surroundings on 6th June 2013. Spatial variations were obviously well captured by the SARA-based DSSR, which is based on higher-resolution SARA AOD. In comparison, the MODISbased DSSR did not capture this variation since it is based on the coarser-resolution MODIS L3 AOD. Not only was the SARA-based DSSR in better agreement with ground-based measurements, it also better represented spatial variations in the landscape.

Comparison of the estimated DSSRs with evaluations from other studies

Our SARA-based DSSR had lower RMSE and bias not only compared with our MODIS-based DSSR but also compared with other similar studies that have used MODIS data products (Table 5). Chen et al. (2014) evaluated the estimated daily average DSSR from MODIS L3 products at 48 BSRN sites under clear-sky conditions. The statistics of daily average DSSR and BSRN observations were $R^{2}=0.87$, RMSE $=29.57 \mathrm{~W} / \mathrm{m}^{2}$, and bias $=12.09 \mathrm{~W} / \mathrm{m}^{2}$. Niu and Pinker (2015) also evaluated estimated 5-km-based DSSR
Table 4 Validation of estimated SARA-based and MODIS-based DSSR with pyranometer measurements at the Koohin site in 2011 and the Chitgar site in 2013

\begin{tabular}{llllcc}
\hline DSSR & Sites & $R^{2}$ & RMSE $\left(\mathrm{W} / \mathrm{m}^{2}\right)$ & Bias $\left(\mathrm{W} / \mathrm{m}^{2}\right)$ & MAPE (\%) \\
\hline SARA-based & Koohin & 0.96 & 23.48 & -2.92 & 2.37 \\
& Chitgar & 0.93 & 20.40 & 3.00 & 1.83 \\
\multirow{2}{*}{ MODIS-based } & Koohin & 0.71 & 52.83 & 24.05 & 4.81 \\
& Chitgar & 0.86 & 49.93 & 43.59 & 5.11 \\
\hline
\end{tabular}




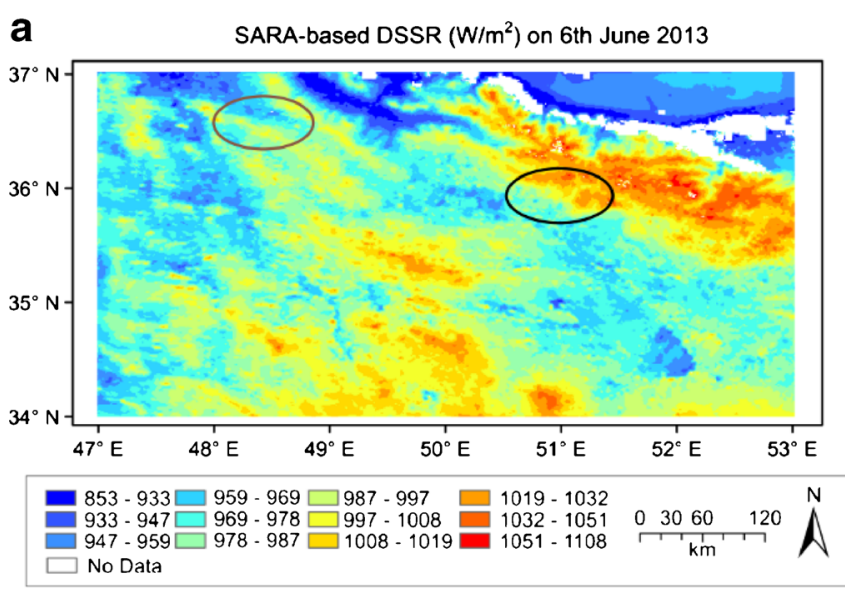

Fig. 7 Spatial patterns in the (a) SARA-based DSSR and (b) MODISbased DSSR on 6th June 2013 over the North of Iran, including the IASBS site in Zanjan (brown oval) and the Chitgar site in Tehran (black

using an updated UMD/MODIS inference scheme against hourly ARM ground observations at a Barrow, Alaska, site for the period March-September 2007. The statistics indicated an RMSE of $58.2 \mathrm{~W} / \mathrm{m}^{-2}$ and a mean bias of $7.9 \mathrm{~W} / \mathrm{m}^{-2}$. Validation of the instantaneous estimated DSSR in Roupioz et al. (2016) showed an $R^{2}$ of 0.89 , an RMSE of $49.8 \mathrm{~W} / \mathrm{m}^{2}$, and a bias of $-11.3 \mathrm{~W} / \mathrm{m}^{2}$ when they used Yang's model along with the MODIS AOD product at the Qomolangma site located on the Tibetan Plateau for the year 2009. Note that the DSSRs validated in our paper are instantaneous values, not hourly or daily means, which makes the results more sensitive to dispersion, especially when evaluated against 30 -min average observations provided by the ground station.

Compared with our study, the RMSEs of other studies are relatively higher except for Chen's study, which provided daily average estimates of DSSR. These errors may be associated with the coarse spatial resolution of the MODIS daily L3 product $\left(1^{\circ}\right)$ and the uncertainty of the MODIS AOD products. Overall, our SARA-based scheme in this study demonstrated high accuracy and consistency of DSSR estimation at the study sites compared with previous similar studies that used the MODIS AOD product based on the DT algorithm. The high spatial resolution and good quality of the SARA AOD can lead to significant improvement of DSSR estimates

Table $5 R^{2}$, RMSE, and bias of estimated DSSR in this study compared with other studies

\begin{tabular}{lllc}
\hline Study & $R^{2}$ & RMSE $\left(\mathrm{W} / \mathrm{m}^{2}\right)$ & Bias $\left(\mathrm{W} / \mathrm{m}^{2}\right)$ \\
\hline Chen et al. (2014) & 0.87 & 29.57 & 12.09 \\
Niu and Pinker (2015) & 0.95 & 58.2 & 7.9 \\
Roupioz et al. (2016) & 0.89 & 49.8 & -11.3 \\
This study (averaged at two sites) & 0.94 & 22 & 3 \\
\hline
\end{tabular}

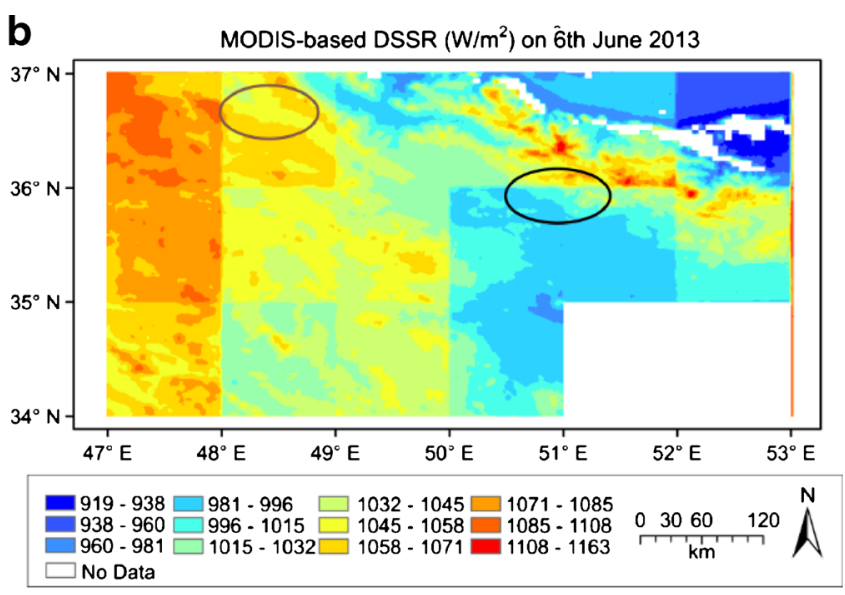

oval). White color means no information because of cloud cover in the left map and no information because of missing values in the MODIS product in the right map

under cloud-free conditions. As was previously mentioned, the high accuracy of the SARA AOD may be attributed to the use of the MODIS TOA and surface reflectance by SARA, which could acquire good information from atmospheric aerosols.

\section{Assessment of the estimated ARF during a dust storm over Southwest Asia}

\section{Estimated SARA AOD}

Figure 8a1, b1 shows MODIS RGB images, and Fig. 8a2, b2 shows the SARA-based AOD over the region on the dusty and non-dusty days. The estimated AOD values in Ahvaz, the Persian Gulf, Al Basrah, and Kuwait City were 1.88, 1.07, 1.40 , and 1.44 , respectively, on the dusty day and were 0.43 , $0.60,0.36$, and 0.45 , respectively, on the non-dusty day. If we compare a1 with b1 and a 2 with b2, we can see how well the SARA-based AOD represented the high and low aerosol conditions on the dusty and non-dusty days. Bilal et al. tested the robustness and accuracy of the SARA algorithm (Bilal et al. 2014) under a severe dust storm in Beijing on 17th April in 2006; they reported that the SARA AOD yielded higher accuracy and reliability than MODIS AOD.

\section{Estimated ARF}

Daily average $\mathrm{ARF}_{\mathrm{DSSR}}$ and $\mathrm{ARF}_{\mathrm{NSSR}}$ values for Ahvaz, the Persian Gulf, Al Basrah, and Kuwait City on the dusty and non-dusty days are shown in Fig. 9. For each site, the absolute value of ARF was much higher on the dusty day compared with the non-dusty day. Higher values resulted because of higher aerosol loadings on the dusty and non-dusty days, and the AOD thus played a determinant role in quantitatively affecting the DSSR. For example, $\mathrm{ARF}_{\mathrm{DSSR}}$ was higher over 
Fig. 8 (a1) MODIS RGB image over Ahvaz, the Persian Gulf, Al Basrah, and Kuwait City on the dusty 4th July; (b1) MODIS RGB image over Ahvaz, the Persian Gulf, Al Basrah, and Kuwait City on the non-dusty 9th July; and (a2) SARA AOD on the dusty 4th July, and (b2) SARA AOD on the non-dusty 9 th July.

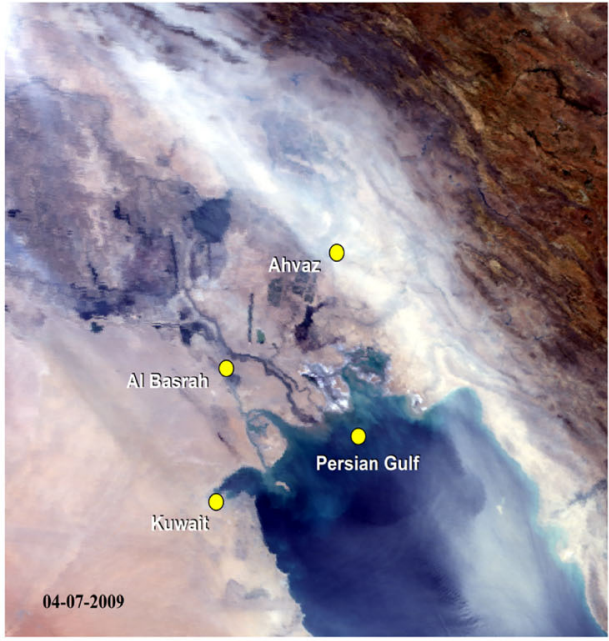

(a1)

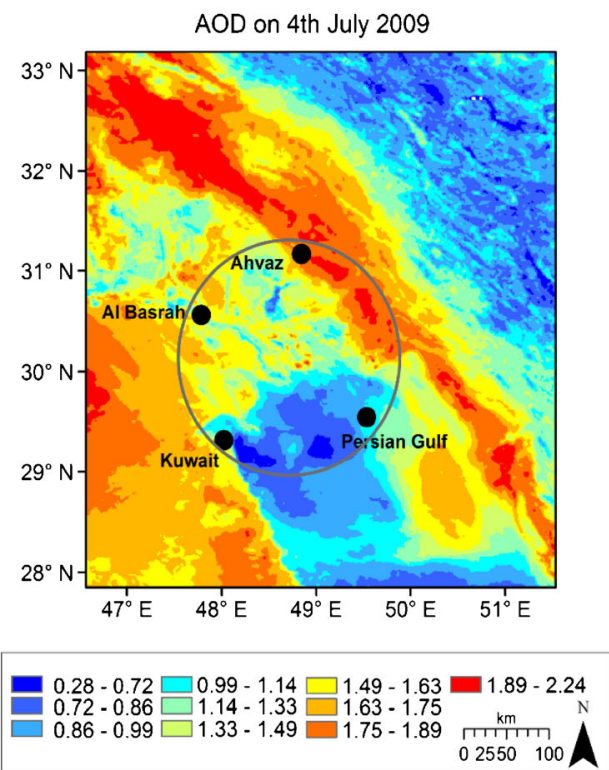

(a2)

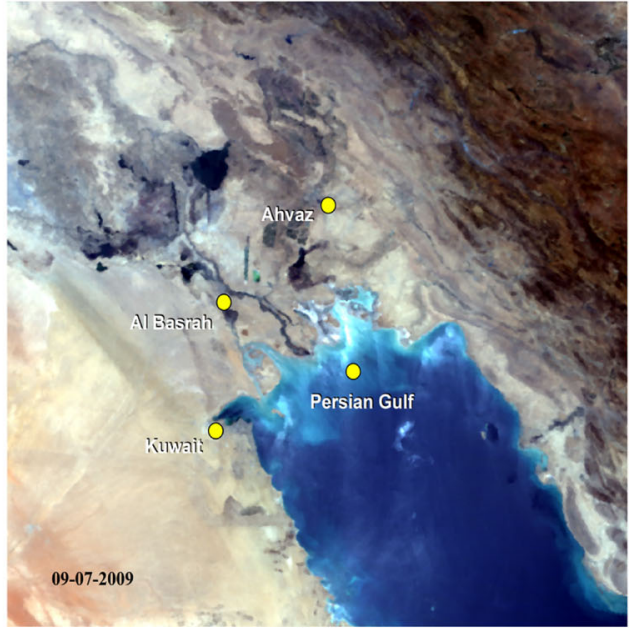

(b1)

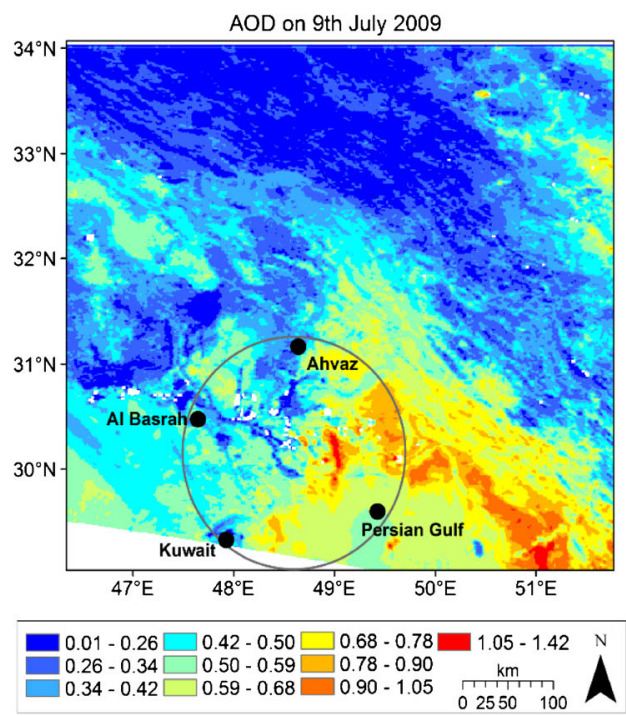

(b2)
Ahvaz compared with the other sites on the dusty day because of a higher aerosol loading (1.07) and was higher over the Persian Gulf on the non-dusty day also because of a higher aerosol loading (0.60). The average $\mathrm{ARF}_{\mathrm{DSSR}}$ for the sites was
$-147 \mathrm{~W} / \mathrm{m}^{2}$ for the dusty day and $-54 \mathrm{~W} / \mathrm{m}^{2}$ for the non-

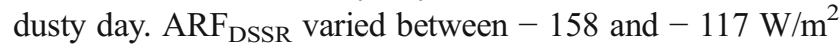
on the dusty day and between -74 and $-51 \mathrm{~W} / \mathrm{m}^{2}$ on the nondusty day (Fig. 9a). The average $\mathrm{ARF}_{\mathrm{NSSR}}$ for the sites was
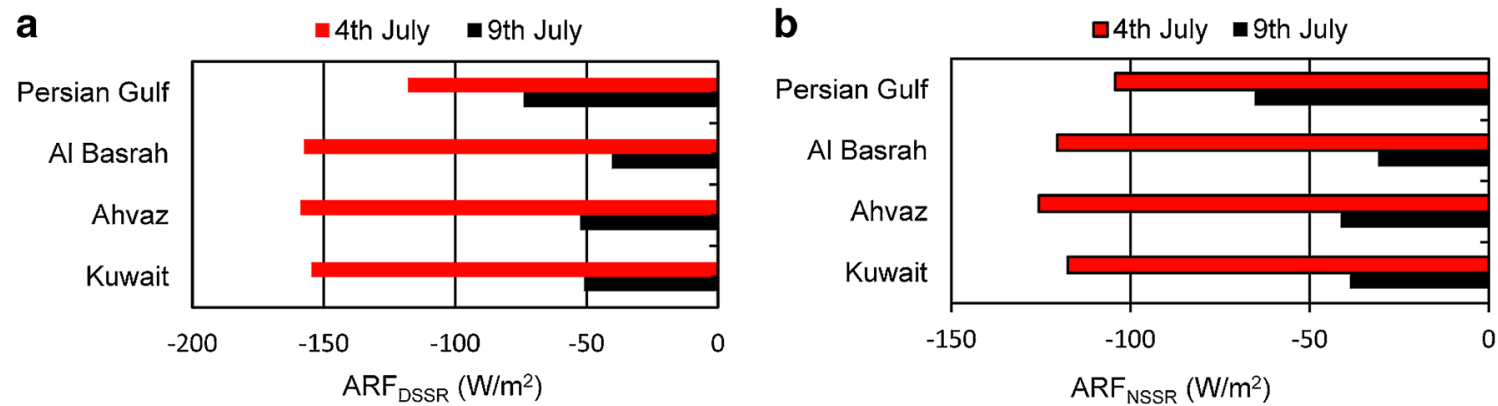

Fig. 9 ARF of the DSSR (a) and NSSR (b) on the dusty 4th July and the non-dusty 9th July in Ahvaz, the Persian Gulf, Al Basrah, and Kuwait City 
$-117 \mathrm{~W} / \mathrm{m}^{2}$ for the dusty day and $-44 \mathrm{~W} / \mathrm{m}^{2}$ for the nondusty day, and the $\mathrm{ARF}_{\mathrm{NSSR}}$ values varied between -126 and $-104 \mathrm{~W} / \mathrm{m}^{2}$ on the dusty day and between -65 and $-31 \mathrm{~W} /$ $\mathrm{m}^{2}$ on the non-dusty day (Fig. 9b).

\section{Comparison of the estimated ARF with estimates from other studies}

The comparison of our ARF estimates with other studies is based on the results provided in three papers: Aher et al. (2014), Alam et al. (2014), and Pandithurai et al. (2008).

Aher et al. (2014) found average $A R F_{D S S R}$ values of $-80 \mathrm{~W} / \mathrm{m}^{2}$ for dusty days and $-52 \mathrm{~W} / \mathrm{m}^{2}$ for non-dusty days over Alibaug in India in 2012. This ARF value on the nondusty day is comparable with our result, whereas the dusty day value is lower than that of our result. The Ahers et al. AOD values on the non-dusty and dusty days were approximately 0.4 and 1.0, respectively, whereas in our study, the average AOD values were 0.46 and 1.45 , respectively; our non-dusty day value is similar to that of Aher et al., whereas the dusty day value is higher. Therefore, the lower ARF on the dusty day over Alibaug could have been because of the lower AOD. As an average for Ahvaz, the Persian Gulf, Al Basrah, and Kuwait City, our results showed on average a 20\% extinction of DSSR for the dusty day compared with the aerosol-free day with the assumption of AOD $=0.1$ at the respective sites. Aher et al. reported an extinction of DSSR by $30-40 \%$ on dusty days compared with non-dusty days in India in 2012.

Alam et al. (2014) found $\mathrm{ARF}_{\mathrm{NSSR}}$ to be $-167 \mathrm{~W} / \mathrm{m}^{2}$ on dusty days and $-98 \mathrm{~W} / \mathrm{m}^{2}$ on non-dusty days over Lahore in Pakistan during a super dust storm that occurred in the Middle East and Southwest Asia in 2012. Pandithurai et al. (2008) studied the ARF during a dust storm over New Delhi in India in 2006 and found average $\mathrm{ARF}_{\mathrm{NSSR}}$ values of $-106 \mathrm{~W} / \mathrm{m}^{2}$ for dusty days in May and $-39 \mathrm{~W} / \mathrm{m}^{2}$ for nondusty days in March. Alam et al.'s ARF $_{\text {NSSR }}$ values from Lahore were higher than those of ours because of the higher AOD values of 2.0 on dusty days and 0.75 on non-dusty days. Pandithurai et al.'s ARF $_{\text {NSSR }}$ values from New Delhi were lower, although still comparable to our results. Their dusty and non-dusty day AOD values were 1.22 and 0.55 , respectively, which are comparable to our AOD values of 1.45 and 0.46 , respectively. Pandithurai et al.'s lower $\mathrm{ARF}_{\mathrm{NSSR}}$ values may instead be explained by how AOD was retrieved; they retrieved AOD data from ground measurements, whereas we retrieved AOD using the SARA algorithm.

\section{Discussion}

Accurate estimates of DSSR at high spatial resolutions are critical for land surface models to simulate surface energy balances in climate change processes (Solomon et al. 2007).
The AOD is the most important input in the estimation of DSSR under cloud-free conditions since it affects the accuracy of DSSR estimates. The objective of this study was to develop an efficient modeling scheme to estimate high-resolution $(1 \mathrm{~km})$ DSSR at the regional scale. Then, high-resolution DSSR could be used as an input to the land surface models.

To estimate high-resolution DSSR from MODIS data, this article modified Iqbal's model $\mathrm{C}$ with the SARA algorithm, which uses TOA radiance and surface reflectance as inputs. The method was further extended to estimate the ARF by assuming stable single scattering albedo and asymmetry factor within the studied region. Validation results showed that the presented hybrid scheme could accurately estimate the instantaneous DSSR at the Koohin and Chitgar sites. Additionally, the reasonably estimated ARF during a dust storm over Southwest Asia demonstrated the usefulness of our modeling scheme. As mentioned earlier, the average RMSE of the instantaneous SARA-based DSSR at the study sites was approximately $22 \mathrm{~W} / \mathrm{m}^{2}$, which is smaller than the error obtained from the MODIS-based DSSR presented in this paper and previous MODIS-based studies as well. The capability of the SARA-based scheme to improve the accuracy of DSSR estimates at the study sites may be because of the high-resolution SARA AOD, which is retrieved from the high-resolution TOA radiance and surface reflectance obtained from MODIS data products and the single scattering albedo and asymmetry factor from the AERONET site. The weaker performance by the MODIS-based scheme may be explained by two reasons: (1) the retrieval algorithms of MODIS AOD products, which overestimate the AOD over the bright land surfaces (Levy et al. 2010), and (2) the coarse resolution of the MODIS L3 AOD product, both of which are discussed in the following sections.

\section{Discussion of the uncertainties and accuracies of MODIS-based and SARA-based DSSR}

The uncertainty and error of the MODIS-derived atmospheric parameters essentially influence the accuracy of the estimated DSSR. The retrieval algorithm of the MODIS atmospheric product yielded relatively low accuracy of the AOD estimates compared with the SARA AOD at the Chitgar site, where an average window of $3 \mathrm{~km} \times 3 \mathrm{~km}$ pixels over the Chitgar site showed that the surroundings consist of bright surfaces (as shown in the "Comparison of estimated AODs at the Chitgar site" section). The retrieval accuracy of aerosol properties is highly influenced by the clouds and bright land surface. Therefore, in addition to the coarse resolution of L3 AOD, the relatively large errors for MODIS-based DSSRs at the study sites shown in the evaluation results may be attributed to these factors.

Another important source of error is the heterogeneity of the atmospheric composition, particularly the aerosol 
properties within the $1^{\circ}$ grid. The heterogeneity effects because of AOD variability impact the estimation of DSSR. The coarse resolution of the MODIS L3 AOD product may be problematic for the application of land surface models at the regional scale and could explain the inconsistency between our MODIS-based DSSR and ground-based observations at the studied sites.

Spatial gaps in the MODIS AOD product also are an important error source in the estimation of DSSR. The complex retrieval of AOD always fails over bright land surfaces, which results in large gaps of AOD values over deserts and causes missing data in DSSR maps, such as gaps over the dried salt lake and surrounding desserts areas in our study region. Therefore, data gaps in the MODIS AOD may be another possible reason for the larger RMSE of the MODIS-based DSSR.

It should be noted that the modeling scheme presented in this paper was used to estimate DSSR only for two groundbased pyranometer sites, assuming a fixed value of the single scattering albedo and asymmetry factor at the regional scale. Future studies should thus include more sites for more robust evaluations. Additionally, the direct and diffuse components of DSSR should be separately evaluated, especially the direct component that depends mainly on the AOD. The assumption of constant single scattering albedo and asymmetry factor at the regional scale could also be an error source for SARAbased DSSR at the Koohin and Chitgar sites, which are approximately 150 and $265 \mathrm{~km}$ away from the AERONET IASBS site, respectively. For the findings of the presented study to be applicable at the regional scale and transferable to the global scale, more AERONET sites are needed to account for the variability of the single scattering albedo and asymmetry factor over wider areas.

Another limitation of this study is that both presented modeling schemes are restricted to only cloud-free conditions. Identifying of cloudy pixels in the SARA-based scheme is based on the LST data product, which is available for only clear-sky pixels. In the MODIS-based scheme, there are many missing pixels because of limitations of the MODIS DT algorithm, which discards pixels not meeting the reflectance criteria, as well as the cloud cover criteria. The MODIS AOD retrieval has a positive bias in AOD because of the cloud fraction, which varies from 10 to $26 \%$ (Hyer et al. 2011). Induced errors because of cloud cover, especially in the MODIS AOD, affect the estimation of DSSR with $1 \mathrm{~km}$ spatial resolution. For findings of the proposed hybrid scheme to be applicable to all-sky conditions, all-sky information for energy balance purposes should be provided. Information provided by data assimilation systems has a relatively good temporal resolution and can aim to provide all-sky AOD, despite their coarse spatial resolution. Generally, the approach proposed in this paper needs to be improved by retrieving allsky AOD, as well as by considering the effects of clouds on
DSSR estimates using the cloud transmittance scheme described by Stephens et al. (1984) and cloud data from the MODIS product.

Overall, the SARA-based DSSR agreed better with ground observations than the MODIS-based DSSR at two distinct study sites, as well as with earlier studies, and therefore should be more suitable for retrieving high-resolution DSSR data at the regional scale during both high- and low-aerosol loading conditions. Another advantage of our proposed hybrid scheme is its capability to retrieve DSSR over all type of surfaces, including bright and dark surfaces; it thus contributes to better estimation of surface energy balances under the likely assumption of future access to all-sky AOD. High-resolution DSSR data can also bridge the gap between existing coarseresolution DSSR products and point-based field measurements and can be used to validate coarse-resolution data.

\section{Discussion of the uncertainties of the ARF estimates}

ARF can be estimated by the calculation of differences in DSSR and NSSR between dusty days and days without aerosols. Therefore, to demonstrate the usefulness of our hybrid scheme during high aerosol conditions, the hybrid scheme was used to estimate the ARF on dusty and non-dusty days during a dust storm that occurred over Southwest Asia.

In previous studies carried out in Pakistan and India, input parameters such as AOD were taken from AERONET sites. However, in our hybrid scheme, the AOD was retrieved by SARA at $1 \mathrm{~km}$ resolution. Although the SARA AOD is not as accurate as AERONET data, its spatial coverage with a high spatiotemporal resolution is an advantage compared with point-based AERONET data. For example, using only one ground-based AOD at the Kuwait University AERONET site does not determine the spatial variation of AOD in Southwest Asia, including Ahvaz, the Persian Gulf, and Al Basrah. In comparison, SARA can estimate the variation in AOD between all sites. Therefore, SARA allows for producing DSSR maps at high spatial resolution, which is necessary to examine ARF at regional and global scales during dust storm events.

Precise radiative transfer models (RTMs), such as the Santa Barbara DISORT atmospheric radiative transfer (SBDART) model, were deployed to calculate ARF on dusty and nondusty days in previous studies, as previously mentioned. In our study, ARF was estimated using our hybrid scheme, which has a rather simple structure compared with RTMs, which may induce uncertainties in ARF estimates. For example, our method does not distinguish between aerosol types that have a considerable impact on the distribution of asymmetrically scattered radiation. However, our estimated ARF is comparable with previous studies, and this simplification may thus be acceptable. Additionally, the modeling scheme does not account for cloud cover since it provides only cloud-free 
information on the AOD. The presented modeling scheme for estimating ARF can be further improved by the incorporation of information on clouds and aerosols and their vertical distribution based on observations from A-train satellites, including the CLOUD SATellite (CloudSat) and the Cloud-Aerosol Lidar and Infrared Pathfinder Satellite Observation satellite (CALIPSO).

\section{Conclusions}

This study estimated downward surface shortwave radiation (DSSR) in the north of Iran and successfully evaluated data with ground-based pyranometer measurements at the Koohin site in 2011 and the Chitgar site in 2013. Iqbal's model C was used to estimate DSSR under cloud-free conditions in two ways: (1) based on the aerosol optical depth (AOD) retrieved from the Simplified Aerosol Retrieval Algorithm (SARA) together with ground-based measurements at the IASBS AERONET site in Zanjan and (2) based on the level 3 (L3) AOD from the Terra MODIS sensor. Several other Terra MODIS land and atmosphere products, including geolocation properties, water vapor, total ozone, surface reflectance, and top-of-atmosphere (TOA) radiance, were also used as input data. The evaluation results were stronger for SARA-based DSSR compared with MODIS-based DSSR at both sites. The lower $R^{2}$ and larger RMSE, MAPE, and bias values for MODIS-based DSSR could be attributed not only to the coarse resolution of MODIS L3 AOD but also to the Dark Target (DT) algorithm, which overestimates AOD over bright land areas. Another advantage of SARA-based DSSR is the higher resolution of $1 \mathrm{~km}$, which is necessary to represent spatial variability in DSSR.

Additionally, we demonstrated the robustness and usefulness of our hybrid modeling scheme by estimating the aerosol radiative forcing $(\mathrm{ARF})$ upon $\mathrm{DSSR}\left(\mathrm{ARF}_{\mathrm{DSSR}}\right)$ and the $\mathrm{ARF}$ upon net surface shortwave radiation $\left(\mathrm{ARF}_{\mathrm{NSSR}}\right)$ for dusty and non-dusty days during a dust storm in Southwest Asia in July 2009. The ARF was estimated for Ahvaz in Iran, the Persian Gulf in Iran, Al Basrah in Iraq, and Kuwait City in Kuwait. The estimated average $\mathrm{ARF}_{\mathrm{DSSR}}$ and $\mathrm{ARF}_{\mathrm{NSSR}}$ values for the dusty and non-dusty days were comparable to values from previous studies by Aher et al. (2014), Alam et al. (2014), and Pandithurai et al. (2008) in Pakistan and India and show the robustness and usefulness of our hybrid scheme.

The purpose of the hybrid scheme proposed in this study was to estimate DSSR with high spatial resolution for use at regional scales. However, such applications require a spatially distributed network of AERONET sites. Using only one AERONET site may create errors in the calculation. However, under the likely assumption of future access to such a network, the results of this study show that the hybrid scheme enables users to efficiently estimate DSSR for modeling and planning purposes in various areas such as land surface and climate models at both regional and global scales. Moreover, for determining a modeling scheme that is applicable to energy balance purposes, all-sky information should be provided, particularly for AOD data. Therefore, in parallel with the more robust evaluation of the approach proposed in this paper by including more sites, it could be further improved by incorporating clouds in the estimation of all-sky DSSR.

Acknowledgements The MODIS data were obtained from the NASA Goddard Space Flight Center, the AOD data from the AErosol RObotic NETwork (AERONET), and solar flux and visibility data from the I.R. of Iran Meteorological Organization (IRIMO).

Open Access This article is distributed under the terms of the Creative Commons Attribution 4.0 International License (http:// creativecommons.org/licenses/by/4.0/), which permits unrestricted use, distribution, and reproduction in any medium, provided you give appropriate credit to the original author(s) and the source, provide a link to the Creative Commons license, and indicate if changes were made.

\section{References}

Aher GR, Pawar GV, Gupta P, Devara PCS (2014) Effect of major dust storm on optical, physical, and radiative properties of aerosols over coastal and urban environments in Western India. Int J Remote Sens 35:871-903. https://doi.org/10.1080/01431161.2013.873153

Alam K, Trautmann T, Blaschke T, Subhan F (2014) Changes in aerosol optical properties due to dust storms in the Middle East and Southwest Asia. Remote Sens Environ 143:216-227

Allen R et al (2007) Satellite-based energy balance for mapping evapotranspiration with internalized calibration (METRIC) - applications. J Irrig Drain Eng 133:395-406. https://doi.org/10.1061/(ASCE) 0733-9437(2007)133:4(395)

Annear RL, Wells SA (2007) A comparison of five models for estimating clear-sky solar radiation. Water Resour Res 43:W10415. https://doi. org/10.1029/2006WR005055

Bilal M, Nichol JE (2015) Evaluation of MODIS aerosol retrieval algorithms over the Beijing-Tianjin-Hebei region during low to very high pollution events. J Geophys Res Atmos 120:7941-7957

Bilal M, Nichol JE, Bleiweiss MP, Dubois D (2013) A simplified high resolution MODIS aerosol retrieval algorithm (SARA) for use over mixed surfaces. Remote Sens Environ 136:135-145. https://doi.org/ 10.1016/j.rse.2013.04.014

Bilal M, Nichol JE, Chan PW (2014) Validation and accuracy assessment of a simplified aerosol retrieval algorithm (SARA) over Beijing under low and high aerosol loadings and dust storms. Remote Sens Environ 153:50-60. https://doi.org/10.1016/j.rse.2014.07.015

Bilal M, Nazeer M, Nichol JE (2017) Validation of MODIS and VIIRS derived aerosol optical depth over complex coastal waters. Atmos Res 186:43-50

Bisht G, Venturini V, Islam S, Jiang L (2005) Estimation of the net radiation using MODIS (moderate resolution imaging spectroradiometer) data for clear sky days. Remote Sens Environ 97:52-67

Bromwich DH, Bai L, Bjarnason GG (2005) High-resolution regional climate simulations over Iceland using polar MM5. Mon Weather Rev 133:3527-3547. https://doi.org/10.1175/MWR3049.1

Carrer D, Lafont S, Roujean JL, Calvet JC, Meurey C, Le Moigne P, Trigo IF (2012) Incoming solar and infrared radiation derived from 
METEOSAT: impact on the modeled land water and energy budget over France. J Hydrometeorol 13:504-520. https://doi.org/10.1175/ JHM-D-11-059.1

Castelli M et al (2014) The HelioMont method for assessing solar irradiance over complex terrain: validation and improvements. Remote Sens Environ 152:603-613. https://doi.org/10.1016/j.rse.2014.07. 018

Chen L, Yan G, Wang T, Ren H, Calbó J, Zhao J, McKenzie R (2012) Estimation of surface shortwave radiation components under all sky conditions: modeling and sensitivity analysis. Remote Sens Environ 123:457-469. https://doi.org/10.1016/j.rse.2012.04.006

Chen M, Zhuang Q, He Y (2014) An efficient method of estimating downward solar radiation based on the MODIS observations for the use of land surface modeling. Remote Sens 6:7136-7157

Chengcai L, Lau AKH, Jietai M, Chu DA (2005) Retrieval, validation, and application of the 1-km aerosol optical depth from MODIS measurements over Hong Kong. IEEE Trans Geosci Remote Sens 43:2650-2658. https://doi.org/10.1109/TGRS.2005.856627

Furman, Kutiel (2003) Dust storms in the Middle East: sources of origin and their temporal characteristics. Indoor Built Environ 12:419-426. https://doi.org/10.1177/1420326X03037110

Gueymard CA (2011) Uncertainties in modeled direct irradiance around the Sahara as affected by aerosols: are current datasets of bankable quality? J Sol Energy Eng 133:031024-031024. https://doi.org/10. $1115 / 1.4004386$

Gueymard CA (2012) Temporal variability in direct and global irradiance at various time scales as affected by aerosols. Sol Resour 86:35443553. https://doi.org/10.1016/j.solener.2012.01.013

Hsu NC, Si-Chee T, King MD, Herman JR (2004) Aerosol properties over bright-reflecting source regions. IEEE Trans Geosci Remote Sens 42:557-569. https://doi.org/10.1109/TGRS.2004.824067

Huang G, Liu S, Liang S (2012) Estimation of net surface shortwave radiation from MODIS data. Int J Remote Sens 33:804-825. https://doi.org/10.1080/01431161.2011.577834

Hubanks P, King M, Platnick S, Pincus R (2008) MODIS atmosphere L3 gridded product algorithm theoretical basis document Collection 005 Version 1.1 vol Tech. Rep. ATBD-MOD-30. NASA

Hyer E, Reid J, Zhang J (2011) An over-land aerosol optical depth data set for data assimilation by filtering, correction, and aggregation of MODIS collection 5 optical depth retrievals. Atmos Meas Tech 4: 379-408

Ichoku C et al (2002) Analysis of the performance characteristics of the five-channel Microtops II Sun photometer for measuring aerosol optical thickness and precipitable water vapor. J Geophys Res Atmos 107:AAC 5-1-AAC 5-17. https://doi.org/10.1029/ 2001JD001302

Iqbal M (1983) Total (broadband) radiation under cloudless skies. In: Iqbal M (ed) An introduction to solar radiation. Academic Press, Toronto, pp 169-213. https://doi.org/10.1016/B978-0-12-3737502.50012-4

IRIMO (2016) I. R. of Iran Meteorological Office. http://www.irimo.ir/. Accessed web page 2016

Kelley C (1995) Iterative methods for linear and nonlinear equations. vol Book, Whole. Society for Industrial and Applied Mathematics. https://doi.org/10.1137/1.9781611970944

Kim H-Y, Liang S (2010) Development of a hybrid method for estimating land surface shortwave net radiation from MODIS data. Remote Sens Environ 114:2393-2402

Kustas WP, Li F, Jackson TJ, Prueger JH, MacPherson J, Wolde M (2004) Effects of remote sensing pixel resolution on modeled energy flux variability of croplands in Iowa 2002 soil moisture experiment (SMEX02) 92:535-547. https://doi.org/10.1016/j.rse.2004.02.020

Lado-Bordowsky O, Naour I (1997) Optical paths involved in determining the scattering angle for the scattering algorithm developed in LOWTRAN7. Int J Infrared Millimeter Waves 18:1689-1696. https://doi.org/10.1007/BF02678280
Levy RC, Remer LA, Dubovik O (2007) Global aerosol optical properties and application to moderate resolution imaging spectroradiometer aerosol retrieval over land. J Geophys Res Atmos 112:D13210. https://doi.org/10.1029/2006JD007815

Levy RC, Remer LA, Kleidman RG, Mattoo S, Ichoku C, Kahn R, Eck TF (2010) Global evaluation of the collection 5 MODIS dark-target aerosol products over land. Atmos Chem Phys 10:10399-10420. https://doi.org/10.5194/acp-10-10399-2010

Li F, Kustas WP, Anderson MC, Prueger JH, Scott RL (2008) Effect of remote sensing spatial resolution on interpreting tower-based flux observations soil moisture experiments 2004 (SMEX04) special issue 112:337-349. https://doi.org/10.1016/j.rse.2006.11.032

Liang S (2004) Quantitative remote sensing of land surfaces, vol Book, Whole. John Wiley \& Sons, Inc., Hoboken. https://doi.org/10.1002/ 047172372X.ch2

Lucht W, Schaaf CB, Strahler AH (2000) An algorithm for the retrieval of albedo from space using semiempirical BRDF models. IEEE Trans Geosci Remote Sens 38:977-998. https://doi.org/10.1109/36. 841980

Ma Y, Pinker RT (2012) Modeling shortwave radiative fluxes from satellites. J Geophys Res Atmos 117:D23202. https://doi.org/10.1029/ 2012JD018332

MODIS (2016) Modis - moderate resolution imaging spectroradiometer. http://modis.gsfc.nasa.gov/. Accessed web page 2016

Moody EG, King MD, Platnick S, Schaaf CB, Feng G (2005) Spatially complete global spectral surface albedos: valueadded datasets derived from Terra MODIS land products. IEEE Trans Geosci Remote Sens 43:144-158. https://doi.org/ 10.1109/TGRS.2004.838359

NASA (2016) NASA earth observatory natural hazards. http://www. earthobservatory.nasa.gov/NaturalHazards/. Accessed web page 2016

Niu X, Pinker RT (2015) An improved methodology for deriving highresolution surface shortwave radiative fluxes from MODIS in the Arctic region. J Geophys Res Atmosp 120:2382-2393. https://doi. org/10.1002/2014JD022151

Pandithurai G, Dipu S, Dani KK, Tiwari S, Bisht DS, Devara PCS, Pinker RT (2008) Aerosol radiative forcing during dust events over New Delhi, India. J Geophys Res Atmos 113:D13209. https://doi.org/10. 1029/2008JD009804

Rahman H, Pinty B, Verstraete MM (1993) Coupled surface-atmosphere reflectance (CSAR) model: 2. Semiempirical surface model usable with NOAA advanced very high resolution radiometer data. $\mathrm{J}$ Geophys Res Atmos 98:20791-20801. https://doi.org/10.1029/ 93JD02072

Roupioz L, Jia L, Nerry F, Menenti M (2016) Estimation of daily solar radiation budget at kilometer resolution over the Tibetan Plateau by integrating MODIS data products and a DEM. Remote Sens 8:504

Ryu Y, Kang S, Moon S-K, Kim J (2008) Evaluation of land surface radiation balance derived from moderate resolution imaging spectroradiometer (MODIS) over complex terrain and heterogeneous landscape on clear sky days. Agric For Meteorol 148:15381552. https://doi.org/10.1016/j.agrformet.2008.05.008

Schaaf CB et al. (2002) First operational BRDF, albedo nadir reflectance products from MODIS. The moderate resolution imaging spectroradiometer (MODIS): a new generation of land surface monitoring. 83:135-148. https://doi.org/10.1016/S0034-4257(02) 00091-3

Sellers PJ et al (1996) A revised land surface parameterization (SiB2) for atmospheric GCMS. Part I: model formulation. J Clim 9:676-705. https://doi.org/10.1175/1520-0442(1996)0092.0.CO;2

Sellers PJ, Dickinson RE, Randall DA et al (1997) Modeling the exchanges of energy, water, and carbon between continents and the atmosphere. Science 275:502-509. https://doi.org/10.1126/science. 275.5299 .502 
Solomon D et al (2007) Climate change 2007: the physical science basis. Cambridge University Press, Cambridge

Stephens GL, Ackerman S, Smith EA (1984) A shortwave parameterization revised to improve cloud absorption. J Atmos Sci 41:687-690

Suri M et al. (2009) Comparison of direct normal irradiation maps for Europe. In: Proc. SolarPACES Conf, Berlin, Germany

Tasumi M, Allen R, Trezza R (2008) At-surface reflectance and albedo from satellite for operational calculation of land surface energy balance. J Hydrol Eng 13:51-63. https://doi.org/10.1061/(ASCE)10840699(2008)13:2(51)
Vermote EF, Vibert S, Kilcoyne H, Hoyt D, Zhao T (2002) Suspended matter. Visible/infrared imager/radiometer suite algorithm theroretical basis document. SBRS document\# Y2390, Raytheon Systems Company Information Technology and Scientific Services, Maryland

Wang T, Yan G, Chen L (2012) Consistent retrieval methods to estimate land surface shortwave and longwave radiative flux components under clear-sky conditions. Remote Sens Environ 124:61-71. https://doi.org/10.1016/j.rse.2012.04.026

Wong MS, Nichol JE, Lee KH (2011) An operational MODIS aerosol retrieval algorithm at high spatial resolution, and its application over a complex urban region. Atmos Res 99:579-589. https://doi.org/10. 1016/j.atmosres.2010.12.015 